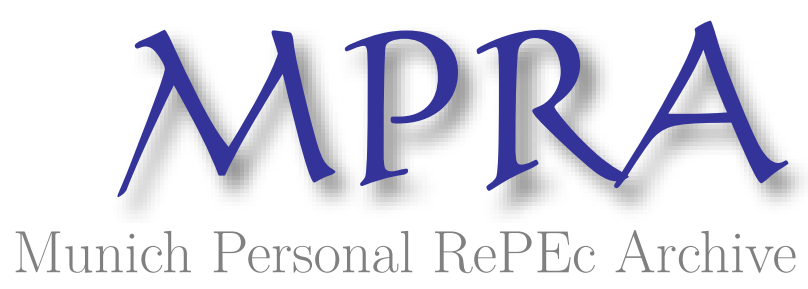

\title{
Why beta shifts as the return interval changes
}

Hawawini, Gabriel

INSEAD

May 1983

Online at https://mpra.ub.uni-muenchen.de/44893/

MPRA Paper No. 44893, posted 09 Mar 2013 15:29 UTC 


\section{Why Beta Shifts as the Return Interval Changes}

A security's beta may vary substantially depending upon whether it is estimated on the basis of daily, weekly or monthly returns. For instance, for the four-year period January 1970 to December 1973, Eastman Kodak had a beta of 1.25 based on daily returns, but a beta of 0.93 based on monthly returns.

In general, the betas of securities with a smaller market value than the average of all securities outstanding (the market) will decrease as the return interval is shortened, whereas the betas of securities with a large market value relative to the market will increase. This suggests that betas measured over return intervals of arbitrary length will tend to be biased. In particular, securities with relatively small market values may appear to be less risky than they truly are, whereas securities with relatively large market values may appear to be more risky than they truly are.

$\mathbf{M}$ ODERN Portfolio Theory (MPT) tells us that a security's historical rates of return can be used to estimate its systematic risk-i.e., its beta coefficient. MPT does not tell us, however, if these rates of return should be measured over a day, a week, a month or any other length of time. Several researchers have shown that this is not a trivial issue. ${ }^{1}$

Beta coefficients have in the past generally been estimated using monthly returns, mainly because these data were the most readily available. ${ }^{2}$ Today, betas may be estimated using weekly or even daily returns. As Table I indicates, however, a beta based on daily returns may differ substantially from a beta based on monthly returns, even if both betas are estimated over the same fixed calendar period.

Here, betas for the four-year period January 1970 to December 1973 have been estimated using 50 monthly returns, 1,009 daily returns and various combinations of weekly returns. For the first firm on the list, Wayne-Gossard, beta based on monthly returns is 0.976 , whereas the daily

1. Footnotes appear at end of article.

Gabriel Hawawini is Professor of Finance at Baruch College of the City University of New York and The European Institute of Business Administration, Fontainebleau, France. beta is 0.459 -a decrease of about 53 per cent. In the case of Eastman Kodak, on the other hand, beta increases by 34 per cent-from 0.932 to $1.251-$ when the return interval is shortened from a month to a day.

This article presents a simple model that explains why estimates of beta depend upon the length of the return interval. This model also predicts the direction and the strength of the variations in estimated betas. Specifically, I will show that when the return interval is shortened, the following occurs: Securities with a smaller market value than the average of all securities outstanding (the market) will generally have a decreasing beta, whereas securities with a larger market value than the average of all securities outstanding will generally have an increasing beta. The implications of this phenomenon for portfolio performance evaluation and estimation of the Security Market Line and the market price of risk reduction are examined.

\section{What Causes Beta to Shift?}

A major factor responsible for shifts in estimated betas is the existence of intertemporal (noncontemporaneous) relationships between the daily returns of individual securities and those of the 
Table I Betas Estimated on the Basis of Various Return Intervals* (January 1970-December 1973)

\begin{tabular}{|c|c|c|c|c|c|}
\hline & $\begin{array}{c}\text { Monthly } \\
\text { Beta }\end{array}$ & $\begin{array}{c}\text { Triweekly } \\
\text { Beta }\end{array}$ & $\begin{array}{c}\text { Biweekly } \\
\text { Beta }\end{array}$ & $\begin{array}{l}\text { Weekly } \\
\text { Beta }\end{array}$ & $\begin{array}{l}\text { Daily } \\
\text { Beta }\end{array}$ \\
\hline Wayne-Gossard & 0.976 & 0.692 & 0.986 & 0.654 & 0.459 \\
\hline Mich. Seamless Tube & 0.973 & 0.883 & 0.917 & 0.784 & 0.433 \\
\hline Publicker Inds. & 1.521 & 1.491 & 1.513 & 1.277 & 1.006 \\
\hline Great West. United & 2.496 & 2.311 & 2.122 & 1.911 & 1.442 \\
\hline Family Finance & 1.268 & 1.324 & 1.212 & 0.821 & 0.795 \\
\hline Bobbie Brooks & 1.874 & 1.889 & 1.818 & 1.592 & 1.405 \\
\hline Monogram Inds. & 2.950 & 2.887 & 2.844 & 2.403 & 2.144 \\
\hline Faberge & 1.882 & 1.511 & 1.511 & 1.416 & 1.449 \\
\hline Dillingham Corp. & 1.004 & 1.164 & 0.990 & 0.750 & 0.725 \\
\hline Vornado & 2.329 & 1.628 & 2.170 & 1.823 & 1.765 \\
\hline Big Three Inds. & 1.339 & 0.970 & 1.283 & 0.969 & 0.712 \\
\hline Cabot Corp. & 0.752 & 0.898 & 0.844 & 0.805 & 0.756 \\
\hline General Development & 1.423 & 1.628 & 1.657 & 1.382 & 1.358 \\
\hline Addresso-Multigraph & 2.094 & 2.341 & 1.566 & 1.414 & 1.733 \\
\hline Great West. Financial & 2.246 & 1.820 & 2.043 & 2.158 & 1.917 \\
\hline Colgate-Palmolive & 1.131 & 1.002 & 1.011 & 0.958 & 0.850 \\
\hline \multicolumn{6}{|l|}{ Aluminium $\mathrm{Co}$. of } \\
\hline America & 1.115 & 1.221 & 1.118 & 1.150 & 1.118 \\
\hline Shell Oil & 0.930 & 1.093 & 0.827 & 0.860 & 0.742 \\
\hline Kresge, S.S. & 1.190 & 1.326 & 1.299 & 1.308 & 1.237 \\
\hline Eastman Kodak & 0.932 & 0.859 & 0.958 & 1.166 & 1.251 \\
\hline
\end{tabular}

*Returns are measured as the logarithm of investment relatives. Market returns are those of the S\&P 500. All betas are statistically significant at the 5 per cent level.

general market. Securities' daily prices do not move in unison; some stocks may lag behind the general market movement, others may lead it. Previous research has suggested that the fundamental cause of these intertemporal crosscorrelations is friction in the trading process, which delays the response of securities' prices to new information. ${ }^{3}$

Table II presents some evidence of this phenomenon. Here the first column gives the contemporaneous correlation coefficient $\left(\rho_{\text {im }}\right)$ between daily security returns and the daily returns of the Standard \& Poor's (S\&P) 500, used as a proxy for the market, $\mathrm{m}$. This coefficient measures the simultaneous association between a security's daily price movements and those of the S\&P 500. The second column gives the intertemporal correlation coefficient with a lag of one day $\left(\rho_{\mathrm{im}}^{-1}\right)$. This measures the strength of the association between today's securities' returns and those of the S\&P 500 one day earlier; in this case, changes in individual prices lag movements in the S\&P 500. The third column gives the intertemporal correlation coefficient with a lead of one day $\left.\left(\rho_{\mathrm{im}}^{+1}\right)\right)^{4}$ The last column gives the ratio of the sum of the two intertemporal correlation coefficients to the contemporaneous correlation coefficient; it is a measure of the strength of intertemporal cross-correlation relative to contem- poraneous correlation. I call this ratio the "q-ratio" of a given security.

The q-ratios of Wayne-Gossard (WG) and Eastman Kodak (EK), for example, are derived as follows:

$$
\begin{aligned}
& \mathrm{q}_{\mathrm{WG}}=\frac{\rho_{\mathrm{WG}, \mathrm{m}}^{-1}+\rho_{\mathrm{WG}, \mathrm{m}}^{+1}}{\rho_{\mathrm{WG}, \mathrm{m}}}=\frac{0.106+0.060}{0.143}=1.161 . \\
& \mathrm{q}_{\mathrm{EK}}=\frac{\rho_{\mathrm{EK}, \mathrm{m}}^{-1}+\rho_{\mathrm{EK}, \mathrm{m}}^{+1}}{\rho_{\mathrm{EK}, \mathrm{m}}}=\frac{0.094+0.189}{0.626}=0.452 .
\end{aligned}
$$

The S\&P 500 itself has a measurable q-ratio, which is equal to:

$$
\mathrm{q}_{\mathrm{m}}=\frac{\rho_{\mathrm{mm}}^{-1}+\rho_{\mathrm{mm}}^{+1}}{\rho_{\mathrm{mm}}}=\frac{2 \rho_{\mathrm{m}}^{-1}}{1}=2(0.285)=0.570
$$

where $\rho_{\mathrm{mm}}^{-1}=\rho_{\mathrm{mm}}^{+1}=$ the autocorrelation coefficient with a lag of one day in the S\&P 500, whose value was found to equal 0.285 over the period January 1970 to December 1973. Since the contemporaneous price movements of the S\&P 500 are perfectly positively correlated with themselves, $\rho_{\mathrm{mm}}=1$, hence the q-ratio of the S\&P 500 equals twice its autocorrelation coefficient.

\section{Importance of the q-Ratio}

The presence of daily intertemporal cross- 
Table II Daily Correlation Coefficients and q-Ratios (January 1970-December 1973)

\begin{tabular}{|c|c|c|c|c|}
\hline & $\rho_{\text {im }}$ & $\rho_{\text {im }}^{-1}$ & $\rho_{\text {im }}^{+1}$ & $\mathrm{q}_{\text {im }}$ \\
\hline Wayne-Gossard & 0.143 & 0.106 & $0.060^{\star}$ & 1.161 \\
\hline Mich. Seamless Tube & 0.165 & 0.177 & $0.044^{*}$ & 1.321 \\
\hline Publicker Inds. & 0.281 & 0.150 & 0.108 & 0.981 \\
\hline Great West. United & 0.233 & 0.131 & 0.096 & 0.974 \\
\hline Family Finance & 0.248 & 0.200 & $0.046^{\star}$ & 0.992 \\
\hline Bobbie Brooks & 0.339 & 0.108 & 0.100 & 0.614 \\
\hline Monogram Inds. & 0.459 & 0.119 & 0.166 & 0.621 \\
\hline Faberge & 0.337 & 0.087 & 0.134 & 0.664 \\
\hline Dillingham Corp. & 0.192 & 0.119 & $0.047^{\star}$ & 0.865 \\
\hline Vornado & 0.391 & 0.225 & 0.124 & 0.893 \\
\hline Big Three Inds. & 0.355 & 0.219 & 0.090 & 0.870 \\
\hline Cabot Corp. & 0.324 & 0.175 & 0.037 & 0.654 \\
\hline General Development & 0.328 & 0.101 & 0.132 & 0.710 \\
\hline Addresso-Multigraph & 0.404 & 0.074 & 0.168 & 0.599 \\
\hline Great West. Financial & 0.546 & 0.176 & 0.180 & 0.652 \\
\hline Colgate-Palmolive & 0.334 & 0.164 & $0.047^{\star}$ & 0.632 \\
\hline \multicolumn{5}{|l|}{ Aluminium Co. of } \\
\hline America & 0.437 & 0.148 & 0.112 & 0.569 \\
\hline Shell Oil & 0.394 & 0.198 & 0.110 & 0.782 \\
\hline Kresge, S.S. & 0.505 & 0.137 & 0.168 & 0.608 \\
\hline Eastman Kodak & 0.626 & 0.094 & 0.189 & 0.452 \\
\hline S\&P 500 & 1.000 & 0.285 & 0.285 & 0.570 \\
\hline
\end{tabular}

*Statistically insignificant at the 5 per cent level.

correlations, whose relative strengths are measured by the q-ratio, causes beta estimates to be related to the length of the return interval. The beta coefficient of security i $\left(\beta_{\mathrm{i}}\right)$, estimated over return intervals of $\mathrm{T}$-day length, is defined as the ratio of the T-day covariance $\left(\sigma_{\mathrm{im}}(\mathrm{T})\right.$ between the returns of $i$ and those of the market index $m$ to the T-day variance $\left(\sigma_{\mathrm{m}}^{2}(\mathrm{~T})\right)$ of the returns of the market index, or:

$$
\beta_{\mathrm{i}}(\mathrm{T})=\frac{\sigma_{\mathrm{im}}(\mathrm{T})}{\sigma_{\mathrm{m}}^{2}(\mathrm{~T})} .
$$

The appendix demonstrates that $\sigma_{\text {im }}(\mathrm{T})$ can be expressed as a function of the daily covariance $\sigma_{\text {im }}(1)$, the length $T$ of the return interval in days, and the security's q-ratio ( $\left.\mathrm{q}_{\mathrm{im}}\right)$ according to:

$$
\sigma_{\mathrm{im}}(\mathrm{T})=\sigma_{\mathrm{im}}(1)\left[\mathrm{T}+(\mathrm{T}-1) \mathrm{q}_{\mathrm{im}}\right] .
$$

An analogous expression can be derived to relate the T-day variance $\sigma_{\mathrm{m}}^{2}(\mathrm{~T})$ to the daily variance $\sigma_{\mathrm{m}}^{2}(1)$ as well as $\mathrm{T}$ and $\mathrm{q}_{\mathrm{m}}$ such that:

$$
\sigma_{\mathrm{m}}^{2}(\mathrm{~T})=\sigma_{\mathrm{m}}^{2}(1)\left[\mathrm{T}+(\mathrm{T}-1) \mathrm{q}_{\mathrm{m}}\right],
$$

where

$$
\mathrm{q}_{\mathrm{m}}=2 \rho_{\mathrm{m}}^{-1},
$$

that is, twice the first order daily autocorrelation coefficient.
Substituting Equations (2) and (3) in Equation (1) gives:

$$
\beta_{i}(\mathrm{~T})=\frac{\sigma_{\mathrm{im}}(1)\left[\mathrm{T}+(\mathrm{T}-1) \mathrm{q}_{\mathrm{im}}\right]}{\sigma_{\mathrm{m}}^{2}(1)\left[\mathrm{T}+(\mathrm{T}-1) \mathrm{q}_{\mathrm{m}}\right]}=\beta_{\mathrm{i}}(1) \frac{\mathrm{T}+(\mathrm{T}-1) \mathrm{q}_{\mathrm{im}}}{\mathrm{T}+(\mathrm{T}-1) \mathrm{q}_{\mathrm{m}}}
$$

Equation (4) clearly shows how intertemporal cross-correlations affect beta as $\mathrm{T}$ varies. First, consider the simple case in which the security's q-ratio and the market's q-ratio both equal zero. In this case, the security's beta over the measurement interval will equal its daily beta, regardless of the length of the return interval. In this highly unlikely situation, beta will be invariant to the length of the return interval. Beta will also be invariant when the security's q-ratio is non-zero and equals that of the market index. This situation may possibly arise. In general, however, a security's q-ratio will differ from the market's, causing beta to change as the return interval varies.

\section{Predicting Direction and Strength of a Beta Shift}

For which securities will beta rise, remain constant or fall as the return interval changes? How strong will the variation in beta be? To answer these questions, we measure the change in the numerator of Equation (4) with respect to the denominator; that is, we measure the response of $\beta_{\mathrm{i}}(\mathrm{T})$ to a small change in $\mathrm{T}$. We have: 


$$
\frac{\mathrm{d} \beta_{\mathrm{i}}(\mathrm{T})}{\mathrm{dT}}=\frac{\beta_{\mathrm{i}}(1)\left[\mathrm{q}_{\mathrm{im}}-\mathrm{q}_{\mathrm{m}}\right]}{\left[\mathrm{T}+(\mathrm{T}-1) \mathrm{q}_{\mathrm{m}}\right]^{2}} .
$$

For beta to decrease as $\mathrm{T}$ is shortened, the change must be positive. This will occur whenever the security's q-ratio is larger than the market's. For beta to increase as the return interval shortens, the change must be negative. This will occur whenever the security's q-ratio is smaller than the market's. Furthermore, beta will decrease faster the larger is the security's q-ratio relative to the market's, and it will increase faster the smaller the security's q-ratio is relative to the market's.

Consider, for example, Wayne-Gossard and Eastman Kodak. The former has a q-ratio of 1.161, far in excess of that of the market index (0.570). As the return interval is shortened, its beta should decrease at a faster rate than the beta of other securities with q-ratios exceeding 0.570 but smaller than 1.161. This is indeed what we observe (see Table I). Eastman Kodak has a qratio of 0.452 , below that of the market index. Its beta should increase as the return interval is shortened. This is again what we observe from Table I. The q-ratio of Aluminium Co. of America equals 0.569 (Table I), which is approximately the value of the q-ratio of the market index. We should expect its beta to remain constant as the return interval varies, and this is indeed the case.

Is there a faster way to tell if beta will shift upward or downward? In other words, is it possible to predict the direction of the shift in beta without knowing its q-ratio? In fact, a security's q-ratio is inversely related to that security's market value of shares outstanding (MVSO). ${ }^{5}$ This means that securities with large MVSO (relative to the market average) will have small q-ratios in comparison to the market. Those with small MVSO (relative to the market average) will have high q-ratios in comparison to the market. Therefore, we may use MVSO (a proxy for a security's relative market thinness) to determine the direction of the shift in beta. Eastman Kodak, with a large MVSO (relatively small q-ratio), will have an increasing beta, and Wayne-Gossard, with a small MVSO (relatively high q-ratio), will have a decreasing beta, when the return interval is shortened. Table II, which lists companies in increasing order of MVSO, illustrates that q-ratios do indeed have a tendency to fall as MVSO rises.

\section{Implications for Analysis}

Because beta estimates depend upon the length of the interval used to measure securities' returns, any computation that incorporates beta may also be affected by the length of the return interval. This includes risk-adjusted measures of investment performance. Consider the performance index suggested by Treynor. ${ }^{6}$ It is the ratio of a portfolio's excess return to its beta. Because beta depends upon the return interval used, so will the performance index. Furthermore, since betas do not usually shift in the same direction, the ranking of portfolios according to the Treynor index may differ depending upon the return interval used.

Another implication concerns the estimation of the Security Market Line of Sharpe and Lintner. ${ }^{7}$ From an estimated SML, one gets the value of the market price of risk reduction (MPR) - that is, the estimated market reward associated with an increase in each unit of risk. If one obtains a monthly estimate of MPR, then it will usually be incorrect to convert this number to an annual basis by simply multiplying by $12 .{ }^{8}$ Likewise, a monthly estimate of MPR cannot usually be converted to a weekly MPR by simply dividing by four.

Finally, because of intertemporal crosscorrelations between securities' price movements, beta estimates will generally depend upon the length of the return interval, implying that betas measured over return intervals of arbitrary length are biased. In particular, securities with large MVSO (relative to the market average) will have estimated betas that are biased upward, whereas securities with small MVSO (relative to the market average) will have estimated betas that are biased downward. ${ }^{9}$ Hence securities with relatively small market values may appear to be less risky than they truly are, whereas securities with relatively large market values may appear to be more risky than they truly are. ${ }^{10}$

\section{Footnotes}

1. See, for example, Bruce D. Fielitz and Myron T. Green, "Shortcomings in Portfolio Evaluation via MPT," Journal of Portfolio Management, Summer 1980, pp. 13-19; Gabriel A. Hawawini, "Intertemporal Cross Dependence in Securities Daily Returns and the Short Run Intervaling Effect on Systematic Risk," Journal of Financial and Quantitative Analysis, March 1980, pp. 139-149; Cheng F. Lee and K. Morimune, "Time Aggregation, Coefficient of Determination, and Systematic Risk of the Market Model," The Financial Review, Spring 1978, pp. 36-47; David Levhari and Haim Levy, "The Capital Asset Pricing Model and the Invest- 
ment Horizon," The Review of Economics and Statistics, February 1977, pp. 92-104; Robert A. Schwartz and David K. Whitcomb, "Evidence on the Presence and Causes of Serial Correlation in Market Model Residuals," Journal of Financial and Quantitative Analysis, June 1977, p. 291-311; and Keith V. Smith, "The Effect of Intervaling on Estimating Parameters of the Capital Asset Pricing Model," Journal of Financial and Quantitative Analysis, June 1978, pp. 313-332.

2. The CRSP tapes compiled at the University of Chicago's Center for Research in Security Prices are typical.

3. Kalman Cohen, Gabriel Hawawini, Steven Maier, Robert Schwartz and David Whitcomb, "Implications of Microstructure Theory for Empirical Research on Stock Price Behavior," Journal of Finance, May 1980, pp. 249-257.

4. Intertemporal correlation coefficients of order higher than the first-not reported in Table IIare usually statistically insignificant. See Gabriel Hawawini, "The Intertemporal Cross Price Behavior of Common Stocks: Evidence and Implications,' Journal of Financial Research, Fall 1980, pp. 153-167.

5. This is demonstrated in Hawawini, "The Intertemporal Cross Price Behavior of Common Stocks."

6. Jack L. Treynor, "How to Rate Management of Investment Funds," Harvard Business Review, January/February 1965, pp. 63-75.

7. William F. Sharpe, "Capital Asset Prices: A Theory of Market Equilibrium Under Conditions of Risk," Journal of Finance, September 1964, pp. 425-442 and John Lintner, "The Valuation of Risk Assets and the Selection of Risky Investments in Stock Portfolios and Capital Budgets," The Review of Economics and Statistics, February 1965, pp. 13-37.

8. See Gabriel A. Hawawini and Ashok Vora, "Temporal Aggregation and the Estimation of the Market Price of Risk," Economics Letters, 1980, pp. 165-170.

9. See Hawawini, "The Intertemporal Cross Price Behavior of Common Stocks."

10. Recent research has suggested some techniques that can possibly be used to correct for this return interval bias. See Kalman Cohen, Gabriel Hawawini, Steven Maier, Robert Schwartz and David Whitcomb, "Estimating and Adjusting for the Intervaling-Effect Bias in Beta,'” Management Science, forthcoming; Elroy Dimson, "Risk Measurement when Shares are Subject to Infrequent Trading, "' The Journal of Financial Economics, 1979, pp. 197-226; and Myron Scholes and Joseph Williams, "Estimating Beta from Non-Synchronous Data," Journal of Financial Economics, 1977, pp. 309-327.

\section{Appendix Derivation of Equation (2)}

To derive Equation (2), write the T-day covariance of the $i$ th security's returns with the returns on a market index $(\mathrm{m})$ as a function of daily returns:

$\sigma_{\mathrm{im}, \mathrm{t}}(\mathrm{T})=\sum_{\mathrm{k}=0}^{\mathrm{T}-1} \sum_{\mathrm{u}=0}^{\mathrm{T}-1} \operatorname{Cov}\left(\mathrm{r}_{\mathrm{t}} \mathrm{T}-\mathrm{k}, \mathrm{i}, \mathrm{r}_{\mathrm{t}} \mathrm{T}-\mathrm{u}, \mathrm{m}\right)$

Equation (A1) is a TxT cross-covariance matrix. Assuming stationarity, its diagonal elements are all equal to the daily contemporaneous covariance denoted $\sigma_{\text {im }}(1)$, and there are $\mathrm{T}$ of those. The off-diagonal elements are intertemporal cross-covariances. Under stationarity, all intertemporal cross-covariances for which the difference $\mathrm{k}-\mathrm{u}=+1$ are equal to $\rho_{\mathrm{im}}^{+1} \sigma_{\mathrm{i}}(1) \sigma_{\mathrm{m}}(1)$, and there are $(\mathrm{T}-1)$ of those. We have assumed that for $\mathrm{k}-\mathrm{u}>+1$, intertemporal cross-covariances are zero. Likewise, all intertemporal cross-covariances for which the difference $\mathrm{k}-\mathrm{u}=-1$ are equal to $\rho_{\mathrm{im}}^{-1} \sigma_{\mathrm{i}}(1) \sigma_{\mathrm{m}}(1)$, and there are $(\mathrm{T}-1)$ of those. Again, for $\mathrm{k}-\mathrm{u}<-1$, intertemporal cross-covariances are zero. From this discussion and Equation (A1) it follows that:

$$
\begin{aligned}
\sigma_{\mathrm{im}}(\mathrm{T})= & \mathrm{T} \sigma_{\mathrm{im}}(1)+(\mathrm{T}-1) \rho_{\mathrm{im}}^{+1} \sigma_{\mathrm{i}}(1) \sigma_{\mathrm{m}}(1) \\
& +(\mathrm{T}-1) \rho_{\mathrm{im}}^{-1} \sigma_{\mathrm{i}}(1) \sigma_{\mathrm{m}}(1)
\end{aligned}
$$

from which Equation (2) in the text follows directly, because

$$
\sigma_{\mathrm{i}}(1) \sigma_{\mathrm{m}}(1)=\sigma_{\mathrm{im}}(1) / \rho_{\mathrm{im}} .
$$

